\title{
Entre el orden 'objetivo' y las subjetividades imaginadas: Reflexiones para el trabajo social
}

\author{
Claudia Garrido Carrasco*
}

RESUMEN

El presente trabajo asume como desafío dialogar en torno a la complejidad que hoy aborda el Trabajo Social. Dicha complejidad viene dada ya no sólo por demandas de equidad e inclusión social, sino también por aquellas referidas a la dimensión subjetiva de la política, en virtud de la constatación de que esa dimensión desoye la emergencia de nuevas formas de participación ciudadana.

Palabras clave: Trabajo Social - inclusión social - dimensión subjetiva de la política

\section{Entre o ordem 'objectivo' e as subjetividades imaginadas: reflexões para o trabalho social}

\begin{abstract}
RESUMO
O presente trabalho, assume como desafio dialogar em torno da complejidad que hoje aborda o Trabalho Social. Dita complejidad, vem dada já não só por demandas de equidad e inclusión social, senão também por aquelas referidas à dimensão subjetiva da política, em virtude da constatación de que essa dimensão desoye a emergencia de novas formas de participação cidadã.
\end{abstract}

Palavras chave: Trabalho Social - inclusión social - dimensão subjetiva da política

\section{Enter the command 'target' and imagined subjectivities: Exploring the social work}

\section{ABSTRACT}

This assignment undertakes assumes as a challenge to converse about complexity that social work approaches today. Such complexity is already given not only by social inclusion and equity demands, but for those referred to the subjective dimension of politics, by virtue of the verification of that dimension disregards the emergence of new ways of civic participation.

Key words: Social work - social inclusion - subjective dimension of politics

* Chilena, Trabajadora Social. Docente Escuela de Trabajo Social Universidad Santo Tomás. Correo electrónico: cgarrido@santotomas.cl 


\section{Antecedentes}

A partir del reciente Informe de Desarrollo Humano en Chile ${ }^{1}$ (PNUD, 2009), es posible constatar la incertidumbre con que la ciudadanía vislumbra el futuro. Hoy, es poco probable que alguien desconozca los avances que el país ha tenido en materias tan sensibles como la reducción en los índices de pobreza, la infraestructura vial, el sistema previsional, la recién inaugurada Ley sobre Acceso a la Información Pública, o las reformas de salud y justicia, entre otros. Y si bien lo anterior permite afirmar que el país se ha modernizado, esa modernización, y esto es ya un lugar común, no ha conseguido incorporar lo que Lechner denominaba "la dimensión subjetiva de la política" (2002).

Lo que el IDH evidencia, es la dificultad de "crear un mundo en común que organice culturalmente a la sociedad" (PNUD, 2009: 14). Ello ocurre por la autonomía creciente con la que los sujetos ejecutan sus acciones y resuelven sus disensos, existiendo allí, una tensión en la relación entre actores, que se refleja en las prácticas sociales.

El Informe ya citado, reclama la urgencia de profundizar esas interacciones, ya que éstas, serían la materia prima con la que se debe trabajar para avanzar; no sólo en la consecución de acuerdos orientados a mejorar objetivamente las condiciones de los sujetos, sino también para la incorporación de subjetividades, entendiendo esa dimensión como "un fenómeno complejo que abarca valores y creencias, disposiciones mentales y conocimientos prácticos, normas y pasiones, experiencia y expectativas" (Lechner, 2002: s/n).

Las nuevas tensiones sociales ubicadas en el cruce de lo político y cultural, plantean al Trabajo Social desafíos relacionados con la (re) lectura de los conflictos, con su procesamiento y con su capacidad de aprehender las lógicas de poder operadas en ellos. Lo anterior, desde un posicionamiento ético que contribuya a otorgar sentido a las identidades de los sujetos, particularmente de aquellos que metafóricamente se encuentran en el extra muro.

1 En adelante, IDH. 


\section{Entre el orden creado y las subjetividades posibles}

"No hay revolucionario político moderno que no haya pensado su rebeldía desde la legitimación democrática de la institución social" (La Voluntad Disculpada, Savater, 1996: 497).

Controversiales son las posiciones existentes en relación a la idea de subjetividad, principalmente porque ésta implica referirse necesariamente a la dimensión cultural y su despliegue en la esfera de lo político. Se tiende a oponer o extremar posiciones, asegurándose por un lado, que los sujetos producen subjetivaciones independiente de sus estructuras sociales, y por otro, que éstas son producidas por aquello que Guattari denomina "las máquinas de producción de subjetividad" (Guattari, 2006).

Al respecto, se entenderá con Canclini (2004), que en la configuración imaginaria de lo social, los procesos y los sujetos pueden tener mucho de construidos y simulados, pero en esas reconstrucciones, también es posible imaginarse actores sociales confiables, cuyas interacciones develen desacuerdos hasta ahora invisibilizados por la estructuración social, que a su vez, actúa como marco de referencia para esos actores.

Lo político y lo cultural no se conciben entonces como lógicas antitéticas, todo lo contrario, se entrelazan; lo peligroso es que lo cultural sea subsumido por lo político, y pierda en ese tránsito su capacidad para dar cuenta de la constitución de los sujetos y sus configuraciones de sentido, precisamente porque es desde ese ámbito desde el cual se recrean nuevas formas de convivencia, razón por la cual, se asume como horizonte una lectura cultural que otorgue pleno reconocimiento a las identidades, entendiendo que éstas se tensionan y producen en dinámicas sociopolíticas.

Fue Lechner (2002), el que a propósito del Informe PNUD² de 1998, llamaba la atención acerca de la no consideración de la subjetividad de las personas, advirtiendo que fenómenos como el miedo a los otros, la erosión del vínculo social, el miedo a la exclusión y al sinsentido, entre otros, eran manifestaciones no incorporadas en la acción política, las cuales, de no procesarse, podían detonar

2 Programa de las Naciones Unidas para el Desarrollo. 
malestares sociales que terminarían redundando en desencanto y pérdida del sentido de representatividad, con lo cual se remitía indefectiblemente a la fragilidad del orden. Esta fragilidad, irrumpe en conjunto con aquella instalada en la emocionalidad de los sujetos, como un "aprendizaje de la descalificación social" (Paugam 2007: 69). O sea, con una introyección de la desprotección, discriminación e inseguridad; ahí radica la forma de conflicto socio-cultural y político, en tanto esos sentimientos pueden devolverse a la escena social en gestos de violencia, indiferencia o descontento, sobre todo cuando las personas "suponen que todos sus comportamientos diarios se interpretan como signos de inferioridad de su estatus, es decir, de una incapacidad social" (Paugam, 2007: 69).

Es en ese cruce en el que "conviene apreciar las articulaciones entre los diferentes niveles de subjetivación” (Guattari, 2006:154).

Según lo anterior, pareciera que hay algo que no logra resolverse o siquiera considerarse en la modernización del país, porque si bien se aprecian sustantivos progresos ${ }^{3}$, éstos tienden a manifestarse en concreciones económicas, donde lo político se aboca a la tarea de tutelar un modelo de desarrollo que no considera como antaño, a los actores sociales; esto implica en palabras de Ruiz, un “desplazamiento de los códigos de interpretación de la sociedad, las mentalidades y el sentido con que se apreciaban ciertas instituciones y procesos sociales" (Ruiz, 2007: 212). Es decir, se mantienen invisibilizados aquellos actos y sujetos en base a los que antiguamente se diseñaba la estructura participativa.

Es precisamente esa no consideración la que actúa como obstáculo para incorporar, procesar y dar sentido a la subjetividad. Al mismo tiempo, el hecho de que los actores no aparezcan en la construcción del progreso, coarta las posibilidades de elaborar marcos de referencia interpretativos de las transformaciones sociales. Parafraseando a Ruiz, las expectativas actuarían como un malestar en la política, impidiendo la gestación de proyectos colectivos (Ruiz, 2007).

Es como si existiese un muro invisible y divisorio entre los que detentan el poder marcando los ritmos del proceso de crecimiento, y aquellos que por omisión se mantienen fuera de esa concepción

3 Para mayor profundización, revisar La Paradoja Aparente (2005), edición a cargo de Patricio Meller. 
política que dibuja los destinos de todos/as. "Ello lleva a una escisión entre el ámbito cotidiano y la sociedad en general (...) esta escisión entre lo cotidiano/comunidad y política/sociedad está en el origen de la pérdida de seguridad que experimentan los individuos" (Ruiz, 2007: 229).

Tal cual lo expresa el IDH (PNUD, 2009), se confirma la autonomización de los individuos, pero se debilitan las prácticas del encuentro social; ello hace opacas las articulaciones de sentido y las creatividades colectivas, no encontrando 'la proyección del yo' una imagen de retorno que confirme la pertenencia a un vínculo social, extraviándose los modos capaces de "asignar significados a la vida que tenemos en común” (Peña, 2007: 38).

No obstante, las configuraciones sociales persisten y se reelaboran entre un orden creado y otro velado, lo que representa un nudo que entrampa el avance hacia una construcción social imaginada comúnmente, al menos en cuestiones tan relevantes como la equidad, las diferenciaciones espaciales, regionales o el acceso a oportunidades; situaciones que vulneran la sensación de pertenencia a un lazo social que en su ideario más democrático, se concibe como no diferenciador ${ }^{4}$ entre categorías de grupos o sujetos.

Ese quebrantamiento en las percepciones de inclusión, se intrinca directamente con los conceptos de ciudadanía y justicia social, pero al mismo tiempo, desnudan una nueva paradoja: no se habla del excluido en directa referencia al pobre, como en la primigenia cuestión social; hoy también se debe considerar a grupos sociales como los indígenas, los jóvenes, los campesinos, los inmigrantes, los discapacitados, las mujeres, los homosexuales, los grupos étnicos y religiosos, definidos por Salas (2003) y Cortina (1997) como las subjetividades sociales emergentes.

Y es paradójico en el sentido que lo constata Canales: "ni pobre ni integrado, oscilando entre una fase y otra, como identidad y figura alterna, uno y otro. Lo mismo globalizado que expulsado, modernizado que descalificado, empleado y desempleado" (Canales, 2007: 195).

4 En este sentido, la diferencia es connotada como exclusión o imposibilidad del Estado, y el poder político en general, de garantizar el derecho de representación de todos los actores sociales. 
Estas minorías del nuevo progreso, como las cataloga el autor recién citado, no es que no articulen su derecho a construir subjetividades y lazos de solidaridad; lo que está ausente es la integración de esas manifestaciones en los espacios más amplios (comunales, regionales y nacionales). Es decir, la expresión se reproduce una y otra vez dentro de fronteras delimitadas por las categorías a las que pertenecen, provocándose así, nuevas formas de conflicto social. "La frontera es (...) una metáfora para una suerte de extranjería interna social, como ciudades que no alcanzan a constituir unidad, y que parecen construidas sobre una desigualdad que las parte. Pero en todas las fronteras hay pasos, idas y vueltas, zonas por ello fronterizas en que lo que comanda no es el estar acá o allá, sino en el traspaso continuo de esas líneas" (Canales, 2007:194).

Pero, ¿cómo ocurre esa producción de subjetividad intra/extra muro? ¿Qué de esa subjetividad penetra al otro lado? ¿Qué queda fuera?

Quizás, habría que interrogarse por el procesamiento que se hace de los encuentros sociales, centrar allí la búsqueda de sentido, en términos de lo que Augé designa como la conciencia recíproca del vínculo instituido con el otro, "poder crear este vínculo con los otros es la condición necesaria para crear la identidad, las identidades. Hoy, cada vez que dudamos del sentido (...) cada vez que hablamos de la crisis de identidad (...) lo que planteamos es la dificultad de pensar el vínculo con los otros" (Augé, 2004: 99).

¿Los sujetos del desencanto, recrean su inconformidad con las categorías naturalizadas? ¿O es precisamente en esa zona donde se evidencia lo irresoluto del conflicto? ¿Será esa conflictividad la que se incluye/excluye a través de la reproducción de una oferta desigual y fragmentada hacia los 'segmentos' sociales?

Probablemente, lo que se precisa es revisar nuevas formas de integración, pero no únicamente concentradas en resolver la desigualdad, puesto que hay elementos que al ser parte de lo sociocultural tienden a no considerarse en la operacionalización políticomoderna de la complejidad social.

La posibilidad de los actores sociales de reconfigurar sentidos, vendrá dada tanto por su capacidad de incluirse en los proyectos Nación, como en deconstruir modos de exclusión, estableciendo nuevos escenarios de convivencia, y evidenciando en esa práctica lo 
que Habermas denomina puntos ciegos de ese proyecto Nación, a partir de su fragmentación política (Habermas, 2000).

Si lo anterior sucede, se pregunta Canales, ¿puede el derecho y el poder emerger como nueva cuestión social? ¿Pueden los actores poner en pregunta al orden? "Desde este tránsito que no conduce, puede fundarse una denuncia cargada de sentido y potencialidad. Es esa queja, también, la base de la desafección profunda de la nueva sociedad respecto a su sistema de representación política" (Canales, 2007: 200-201).

La pregunta por el surgimiento de una nueva cuestión social, transita por la incomoda certeza de que existe una política que se ha desplazado hacia otros horizontes, ensimismada tal vez en la fórmula del crecimiento con equidad. El nudo crítico se presenta, tal como lo advierte Camargo (2007), en la reducción de la idea de equidad al resultado del crecimiento, donde opera sólo como prescripción política, dejando fuera la dimensión del poder posibilidad de imaginar nuevos ordenamientos de poder" (Camargo, 2007: 15). Lechner coincide con ese planteamiento, enfatizando en que lo anterior negaría a los sujetos la opción de decidir acerca de los fines de su acción; ello sería "negar la política en tanto construcción deliberada del orden social" (Lechner, 2002: s/n).

En esa disyuntiva, aparece la pregunta por la capacidad deliberativa de los actores sociales, y la manera en que éstos crean, modifican, se someten o rebelan frente al progreso, el que al decir de Lyotard, "se extiende hacia ellos, mientras [el pueblo] está en debate consigo mismo acerca de lo que es justo o injusto (...) acumula las leyes civiles (...) perfecciona las reglas de su consenso por disposiciones constitucionales (...) produciendo nuevos paradigmas" (Lyotard, 1998: 60).

No obstante, dirá Habermas, los sujetos neoliberales -o construidos por esa teoría- son sujetos que necesitan interesarse recíprocamente, pero no están dotados para interesarse por el otro, en un sentido moral. Ello "puede explicar una cierta despreocupación en cuestiones de justicia social, una actitud que oscila entre la tolerancia, la indiferencia y el cinismo" (Habermas, 2000: 124).

5 El poder gestionado y articulado por los sujetos. 
Develado ese problema, cabe preguntarse por las posibilidades de construcciones íntegramente democráticas que articulen subjetividades basadas en la justicia social. Si bien Habermas (2000) apunta a las ideas de soberanía popular y derechos humanos y entiende la validez de la democracia en virtud de la justicia social, dichos procesos no podrán aspirar a ser legitimados si el poder político se mantiene concentrado exclusivamente en la eficiencia medio-fin. Entonces, debe aspirarse a que el derecho producido pueda ser reconocido para asegurar la armonía de las relaciones y la autonomía de los sujetos, tanto en el ámbito privado como en su concepción de ciudadanos.

Savater señala que "las reivindicaciones democráticas acosan al Estado con sus ingenuidades radicales, mientras éste se encastilla en un reforzamiento autocrático que no puede ni prescindir de la legitimación igualitaria ni hacerse compatible en la práctica con ella" (Savater, 1996: 498). Pese a todo, se hace urgente la demanda por articular identidades que permitan ejecutar prácticas e idear soluciones entre todos/as, entendiendo que la vivencia plena de la ciudadanía "debe integrar una identidad, por la que una persona se sabe y siente perteneciente a una sociedad" (Cortina, 1997).

\section{Reflexiones Finales}

Como se ha revisado, abordar la conflictividad social a través de la esfera política, implica tensionar un tipo de racionalidad que hegemoniza la relación con los actores sociales, a los cuales incorporan desde una lógica centrada en el beneficio, por sobre otra imaginada como creativa, crítica, y plena de sentidos. Como dijera Savater: "hay poco razonamiento político, hay poca educación política (...) a los ciudadanos se les mantiene alejados de cómo funciona el sistema que ellos deben gestionar y donde deben participar" (Savater, 1998: 242).

Pero hay en la lógica recientemente descrita, una contrariedad para avanzar plenamente hacia lo que se entiende como Estado democrático y ciudadanizante, y ello es; que los intercambios sociales se ponen en entredicho cuando no recogen las subjetivaciones de los sujetos, o cuando minimiza una creciente autonomía porque la concibe como efecto residual de la modernización. 
No obstante, lo que el Informe de Desarrollo Humano en Chile (2009) plantea hoy como imperativo, es la necesidad de incorporar a los actores sociales, pensando en que esa integración podrá desencadenar procesos de largo aliento, donde los/as ciudadanos se sientan parte de un proyecto Nación.

El desafío anterior, demanda para el Trabajo Social la urgente tarea de leer las complejidades socioculturales, y desde su acervo crítico, ético, metodológico y epistemológico, develar configuraciones sociales, visibilizando las diferencias y procesándolas para construir nuevas convivencias.

La tarea para el Trabajo Social, puede estar orientada por las preguntas que planteara Jamur para la disciplina; ¿qué nuevos escenarios, actores, racionalidades o principios pueden ser utilizados para una nueva construcción de lo social? ¿Cuáles son las condiciones objetivas de reformulación? (Jamur, 1997).

El reto para el Trabajo Social, debe orientarse a la construcción de una Política Social que considere "los ejes valórico-normativos del reconocimiento de todo sujeto como sujeto de derechos y digno per se; el eje de la justicia social, como condición de posibilidad para ese reconocimiento y el ejercicio de las libertades; así como también, la necesidad de apuntar hacia una nueva convivencialidad desde una redefinición de la responsabilidad solidaria" (Mideplan, 2000). Todo ello, para dotar de sentido las prácticas sociales, ellas son la materia prima de la transformación.

\section{Referencias bibliográficas}

Augé, M. (2004). ¿Por qué vivimos? Por una antropología de los fines. España: Gedisa

Camargo, R. (2007). Del "Crecimiento con Equidad" al "Sistema de Protección Social": La Matriz Ideológica del Chile Actual (1990-2007). Revista de Sociología, 21. Recuperado el 09 de abril, 2009. De http://www.facso.uchile.cl/publicaciones/ sociologia/docs/revsoc21.pdf

Canales, M. (2007). Ni pobres ni incluidos: ¿nueva cuestión social? Revista de Sociología, 21. Recuperado el 09 de abril, 2009. De http://www.facso.uchile.cl/publicaciones/ sociologia/docs/revsoc21.pdf 
Chile. Ministerio de Planificación y Cooperación y Centro de Ética Universidad Alberto Hurtado. (2000). El porvenir de la equidad: una contribución desde el debate filosófico y contemporáneo. Santiago, Chile: Autor.

Cortina, A. (1997). Ciudadanos del Mundo. Hacia una teoría de la ciudadanía. España: Alianza.

García Canclini, N. (2004). Diferentes, Desiguales y Desconectados. Mapas de la interculturalidad. España: Gedisa.

Guattari, F., Rolnik S. (2006). Micropolítica. Cartografías del deseo. Madrid: Traficantes de Sueños.

Habermas, J. (2000). La Constelación Posnacional. Ensayos Políticos. España: Paidós.

Jamur, M. (1997). Reflexòes sobre uma esfera construída e conflictual: "o social". Río de Janeiro: PUC.

Lechner, N. (2002). Las sombras del mañana. La dimensión subjetiva de la política. Santiago, Chile: Lom.

Lyotard, J. (1998). La condición postmoderna. Madrid: Cátedra.

Paugam, S. (2007). Las formas elementales de la pobreza. Madrid: Alianza.

Peña, C. (2007). Chile actual: el proyecto político de la Concertación. Revista de Sociología, 21. Recuperado el 09 de abril, 2009. De

http://www.facso.uchile.cl/publicaciones/ sociologia/docs/revsoc21.pdf

Programa de las Naciones Unidas para el Desarrollo. (2009). La manera de hacer las cosas. Documento de Síntesis. Santiago, Chile: Autor.

Ruiz, C. (2007). Actores Sociales y transformación de la estructura social. Revista de Sociología, 21.Recuperado el 09 de abril, 2009. De

http://www.facso.uchile.cl/publicaciones/ sociologia/docs/revsoc21.pdf

Salas, R. (2003). Ética Intercultural (Re) Lecturas del Pensamiento latinoamericano. Santiago, Chile: Universidad Católica Silva Henríquez.

Savater, F. (1996). La voluntad disculpada. España: Taurus. (1998). Ética y Ciudadanía. España: Monte Ávila. 